\title{
CARACTERIZAÇÃO E SENSIBILIDADE DE CEPAS DE Escherichia coli ISOLADAS DO LEITE PROVENIENTE DE TANQUES RESFRIADORES DE PEQUENAS PROPRIEDADES DO MUNICÍPIO DE CANGUÇU - RS
}

\author{
PETER, Cristina Mendes ${ }^{1}$; \\ PICOLI, Tony ${ }^{2}$; \\ PERES, André Fernandes ${ }^{3}$; \\ CZERMAINSKI, Leonardo Arrocho ${ }^{4}$; \\ RIPOLL, Márcia Kutscher ${ }^{4}$; \\ BRAGATO, Mirele da Silva ${ }^{4}$; \\ ZANI, João Luiz ${ }^{5}$.
}

\footnotetext{
${ }^{1}$ Médica Veterinária, Mestra, Residente em Saúde Coletiva, Faculdade de Veterinária, UFPEL; ${ }^{2}$ Médico Veterinário, Mestre, Programa de Pós-Graduação em Veterinária, UFPEL; ${ }^{3}$ Médico Veterinário autônomo; ${ }^{4}$ Graduando em Veterinária, UFPEL; ${ }^{5}$ Médico Veterinário, Professor, Doutor, Departamento de Veterinária Preventiva, Faculdade de Veterinária, UFPEL.
}

\section{RESUMO}

\begin{abstract}
A Escherichia coli é uma enterobactéria Gram-negativa com potencial patogênico, podendo ser encontrada em alimentos, sendo responsável principalmente por quadros diarreicos em crianças, adultos imunossuprimidos e também em animais. Este trabalho teve por objetivo identificar a presença de $E$. coli no leite cru colhido de tanques resfriadores, de pequenas propriedades rurais do município de Canguçu, Rio Grande do Sul e avaliar a sua sensibilidade frente a antimicrobianos usualmente utilizados para tratamento de infecções ocasionadas por este microrganismo. A análise sorológica identificou $E$. coli enteropatogênica (ETEC) em $42,5 \%$ dos isolados e $E$. coli enteroinvasiva (EIEC) em 32,5\%. Nas análises de biossensibilidade, os melhores resultados foram obtidos com os antimicrobianos sulfazotrim e imipenem, ambos com $80 \%$ de eficiência. Em relação à resistência, 57,5\% dos isolados apresentaram resistência à cefotaxima e $47,5 \%$ à gentamicina e ao ácido nalidíxico. Os isolados apresentaram baixa resistência a alguns antimicrobianos normalmente utilizados para tratamento da colibacilose em humanos e em animais.
\end{abstract}

Palavras-chave: Antibiograma. Sorologia. Saúde pública. Leite cru. 


\section{INTRODUÇÃO}

O leite, juntamente com seus derivados, é um dos alimentos mais consumidos no mundo. De acordo com a Organização das Nações Unidas para Alimentação e Agricultura (FAO) e a Organização Mundial da Saúde (OMS), o consumo desejável de leite e derivados, por adulto por ano, é de cerca de 200 litros (equivalentes), mas a média brasileira está abaixo do recomendado, 140 e 160 litros por habitante por ano (FAO, 2015; OMS, 2016).

O Brasil é o quarto maior produtor mundial de leite, com 34 bilhões de litros em 2013 (BRASIL, 2015). Segundo dados do Instituto Brasileiro de Geografia e Estatística (IBGE), a aquisição de leite cru feita pelos estabelecimentos que atuam sob inspeção federal, estadual ou municipal, no Brasil, durante o 1 o trimestre de 2016, foi de 5,86 bilhões de litros. Em relação à produção nacional de leite por regiões, no 10 trimestre de 2016, a Região Sudeste contribuiu com 41,4\%, a Região Sul com 35,2\%, a Centro-Oeste com 13,7\%, a Nordeste com $4,9 \%$ e a Norte com 4,8\% (IBGE, 2016).

A qualidade do leite é influenciada diretamente pela saúde da glândula mamária, pela higiene da ordenha, pela forma como é realizada a limpeza do equipamento de ordenha e pelo sistema de armazenamento (FONSECA; SANTOS, 2000). Os alimentos crus, especialmente o leite, frequentemente são contaminados com Escherichia coli. Essa contaminação geralmente ocorre pelas mãos do manipulador e/ou equipamentos (SCABIN et al., 2012).

A E. coli é uma bactéria Gram-negativa, que faz parte do grupo das enterobactérias e está presente no lúmen intestinal de seres humanos e de animais, sua colonização no trato intestinal de mamíferos ocorre a partir de fontes ambientais logo após o nascimento. Apesar de a maioria das cepas serem comensais, algumas cepas de $E$. coli adquiriram modificações genéticas (genes de virulência) que resultaram num aumento da patogenicidade para humanos e animais. As cepas responsáveis por causar enterocolites geralmente não fazem parte da microbiota normal de animais saudáveis, sendo adquiridas através de contato direto com animais portadores, ou ingestão de alimentos e água contaminados (KASNOWSKI et al., 2007). 
Algumas cepas de $E$. coli possuem potencial patogênico, as quais são divididas em patotipos, de acordo com o tipo de toxina produzida e as doenças específicas que causam, podendo ser gastroenterite ou doenças extra intestinais. Dentre essas cepas causadoras de gastroenterite em seres humanos, a combinação de fatores de virulência possibilita sua classificação em seis patotipos: E. coli enterotoxigênica (ETEC), E. coli enteroagregativa (EAEC), E. coli de aderência difusa (DAEC), E. coli enteroinvasiva (EIEC), E. coli enteropatogênica (EPEC) e $E$. coli produtora de Shiga toxina (STEC) (HUANG et al., 2006).

A sorotipagem ocupa um lugar de destaque no estudo deste microrganismo. Kauffmam (1944 apud NATARO; KAPER, 1998) propôs um esquema para a classificação sorológica de $E$. coli, o qual utiliza-se até os dias atuais. De acordo com o esquema, as $E$. coli são sorotipadas com base em seu antígeno somático $(\mathrm{O})$, flagelar $(\mathrm{H})$ e capsular $(\mathrm{K})$, sendo que a quantidade de diferentes antígenos identificados acresce a cada ano. Até o momento foram identificados 171 diferentes antígenos O. Uma combinação específica de antígenos $\mathrm{O}$ e H define o sorotipo de uma linhagem, enquanto que na identificação perfunctória apenas o antígeno O é utilizado para definição do sorogrupo da linhagem (NATARO; KAPER, 1998).

Este trabalho teve por objetivo identificar a presença de E. coli no leite cru colhido de tanques resfriadores, de pequenas propriedades rurais do município de Canguçu, Rio Grande do Sul e avaliar a sua sensibilidade frente a antimicrobianos usualmente utilizados para tratamento de infecções ocasionadas por este microrganismo.

\section{MATERIAL E MÉTODOS}

\section{Local do trabalho}

O trabalho foi realizado no município de Canguçu (latitude $31^{\circ} 23^{\prime} 42^{\prime \prime}$ sul, longitude $52^{\circ} 40^{\prime} 32^{\prime \prime}$ oeste), mesorregião sudeste do estado do Rio Grande do Sul, durante o ano de 2013. O município possui o maior número de minifúndios do Brasil, cerca de 14 mil propriedades rurais, sendo reconhecido como a Capital Latino-Americana da Agricultura Familiar (IBGE, 2013, 2016). 


\section{Coleta das amostras}

Foram coletadas 78 amostras de leite cru de 78 Unidades Produtoras de Leite (UPL), uma amostra por propriedade, diretamente dos tanques de resfriamento, sendo mantidas sob refrigeração para posterior processamento no laboratório. Previamente à coleta da amostra, o leite foi homogeneizado durante cinco minutos em tanques de expansão, com uso de homogeneizador inoxidável de cabo longo em resfriadores de imersão, ou com o uso de agitador. As amostras então foram armazenadas em frascos estéreis de polietileno, identificadas e acondicionadas em caixa isotérmica com gelo reutilizável para transporte até o Laboratório de Bacteriologia e Saúde Populacional (LABASP) da Faculdade de Veterinária da Universidade Federal de Pelotas (UFPEL) para análise microbiológica.

\section{Isolamento e identificação de Escherichia coli}

Para o processamento e análise microbiológica das amostras, estas sofreram quatro diluições em solução salina $0,85 \%$ estéril, na base 10 , para serem então semeadas com micropipeta calibrada de $100 \mu \mathrm{l}$ em dois meios, ágar MacConkey (Oxoid ${ }^{\circledR}$ ) e ágar Eosina-Azul de Metileno (EMB) (Himedia ${ }^{\circledR}$ ) ambas em duplicata e então incubadas a $37^{\circ} \mathrm{C}$ por 48 horas. As colônias que apresentaram desenvolvimento com aspecto róseo em MacConkey e com coloração metálica em EMB foram consideradas compatíveis com E. coli. Essas colônias foram repicadas em meio de cultura ágar sangue contendo $5 \%$ de sangue ovino desfibrinado, e mantidas em estufa bacteriológica a $37^{\circ} \mathrm{C}$ por 24 horas, para caracterização bioquímica segundo Quinn et al. (2011).

\section{Identificação sorológica dos isolados de Escherichia coli}

Para identificação sorológica foi utilizado o método de soroaglutinação em lâmina com três soros polivalentes contra E. coli enteropatogênica (EPEC): soro Polivalente A (PA) (sorogrupos 026, 055, 0111, 0119), soro Polivalente B (PB) (sorogrupos 0114, 0125, 0142, 0158), soro Polivalente C (PC) (sorogrupos 086, 0126, 0127, 0128); e dois soros polivalentes contra E. coli enteroinvasora (EIEC): soro Polivalente Invasora A (IA) (sorogrupos O28ac, O29, 0136, 0144, 0152), soro Polivalente Invasora B (IB) (sorogrupos O112ac, 0124, 0143, 0164, 0167). O teste foi conduzido conforme descrição do fabricante (PROBAC ${ }^{\circledR}$, 
2016). As amostras que não aglutinaram com nenhum dos antissoros foram agrupadas como Não Reagentes (NR).

O teste de soroaglutinação foi realizado em lâminas de vidro estéreis, na qual foram misturadas uma alíquota da suspensão bacteriana na turbidez 02 da escala de Mac Farland e uma gota do antissoro. A reação foi considerada positiva quando houve aglutinação na lâmina dentro do período de dois minutos. Para o controle dos testes de sorotipificação e sensibilidade dos isolados foi utilizada a cepa E. coli ATCC (25922).

\section{Teste de sensibilidade a antimicrobianos em isolados de Escherichia coli}

O grupo de isolados de $E$. coli obtidos do leite das pequenas propriedades foi testado quanto à sensibilidade frente a antimicrobianos, pelo teste de difusão em ágar Mueller-Hinton $\left(\mathrm{Oxoid}^{\circledR}\right)$, realizado e interpretado de acordo com as normas do National Committee for Clinical Laboratory Standards (NCCLS, 2003). Doze antimicrobianos foram selecionados, representando oito diferentes grupos farmacológicos, disponíveis em discos impregnados comerciais (Sensidisc ${ }^{\circledR}$ ): Aminoglicosídeos - amicacina $30 \mu \mathrm{g}$ (AMI) e gentamicina $10 \mu \mathrm{g}$ (GEN); Carbapenemas - imipenem $10 \mu \mathrm{g}$ (IPM); Cefalosporinas - cefepime $30 \mu \mathrm{g}$ (CPM) e cefotaxima $30 \mu \mathrm{g}$ (CTX); Inibidores de Folato - sulfametoxazol+trimetropim $25 \mu \mathrm{g}$ (SUT); Nitrofurantoínas - nitrofurantoína $300 \mu \mathrm{g}$ (NIT); Penicilinas - ampicilina $10 \mu \mathrm{g}$ (AMP); Polimixinas - polimixina B $300 \mu \mathrm{g}$ (POL); Quinolonas - ácido nalidíxico $30 \mu \mathrm{g}$ (NAL), ciprofloxacina $05 \mu \mathrm{g}(\mathrm{CIP})$ e norfloxacina $10 \mu \mathrm{g}$ (NOR).

\section{Análise dos resultados}

Os resultados de isolamento, sorotipificação e testes de sensibilidade dos isolados de $E$. coli foram analisados quanto à frequência encontrada e expressos em porcentagem. Utilizou-se o programa Excel ${ }^{\circledR}$ para tabulação e análise dos resultados obtidos.

\section{RESULTADOS E DISCUSSÃO}

Das 78 amostras de leite colhidas isolou-se E. coli, nos meios seletivos, em 40 delas $(51,28 \%)$. Resultado semelhante foi encontrado por Virpari et al. (2013), que isolaram E. coli de $52 \%$ das amostras de leite cru em um estudo realizado na Índia. Valores mais elevados 
encontraram Campos et al. (2006), que avaliaram 24 amostras de leite cru e verificaram a presença de $E$. coli em 79,2\% das amostras em um laticínio no estado de Goiás.

Barreto et al. (2012) coletaram amostras de leite cru em estabelecimentos comerciais na cidade de Cruz das Almas no estado da Bahia, e como resultados obtiveram o isolamento de E. coli em $76 \%$ das amostras. Os autores atribuíram a esse elevado índice de isolamentos, a exposição a maiores temperaturas que o leite amostral foi submetido desde a ordenha até o estabelecimento comercial, o que não ocorreu no levantamento do município de Canguçu, já que o leite foi colhido na propriedade rural, sob refrigeração, com no máximo 48 horas de armazenamento. Os dados de Barreto et al. evidenciam a grande contaminação por $E$. coli no leite cru, o que pode ser atribuído às variações nas condições de armazenamento, de higiene da ordenha, do ordenhador, dos tarros, tubulações e ordenhadeiras.

Como resultado da sorotipificação dos isolados do presente estudo, observou-se que: $12,5 \%$ aglutinaram com o soro Polivalente A, 22,5\% aglutinaram com o soro Polivalente B, 7,5\% aglutinaram com o soro Polivalente C, $15 \%$ aglutinaram com o soro Polivalente Invasora A, 17,5\% aglutinaram com o soro Polivalente Invasora B e $25 \%$ das amostras não aglutinaram frente a nenhum soro (Figura 1). Silva et al. (2001), analisaram 90 amostras de leite tipos B e C, pasteurizados, de três marcas distintas na cidade do Rio de Janeiro, sendo que de 37 amostras $(41,1 \%)$ foram isoladas 208 colônias de E. coli, 46 colônias $(22,1 \%)$ foram identificadas como E. coli enteropatogênica. Demonstrando o risco potencial desse tipo de alimento para a saúde pública e evidenciando a necessidade de uma maior vigilância sobre o processo de pasteurização nas indústrias de laticínios.

Okura et al. (2005) analisaram 324 amostras de leite cru de uma Cooperativa do município de Uberaba, Minas Gerais, sendo que de 245 amostras (75,6\%) foram isoladas 327 cepas de vários gêneros ou espécies de bactérias, das quais, 70 isolados $(21,4 \%)$ foram identificados como E. coli, entretanto nenhum deles apresentou aglutinação com os soros polivalentes $A$, $B$ e C de E. coli enteropatogênica (EPEC). 


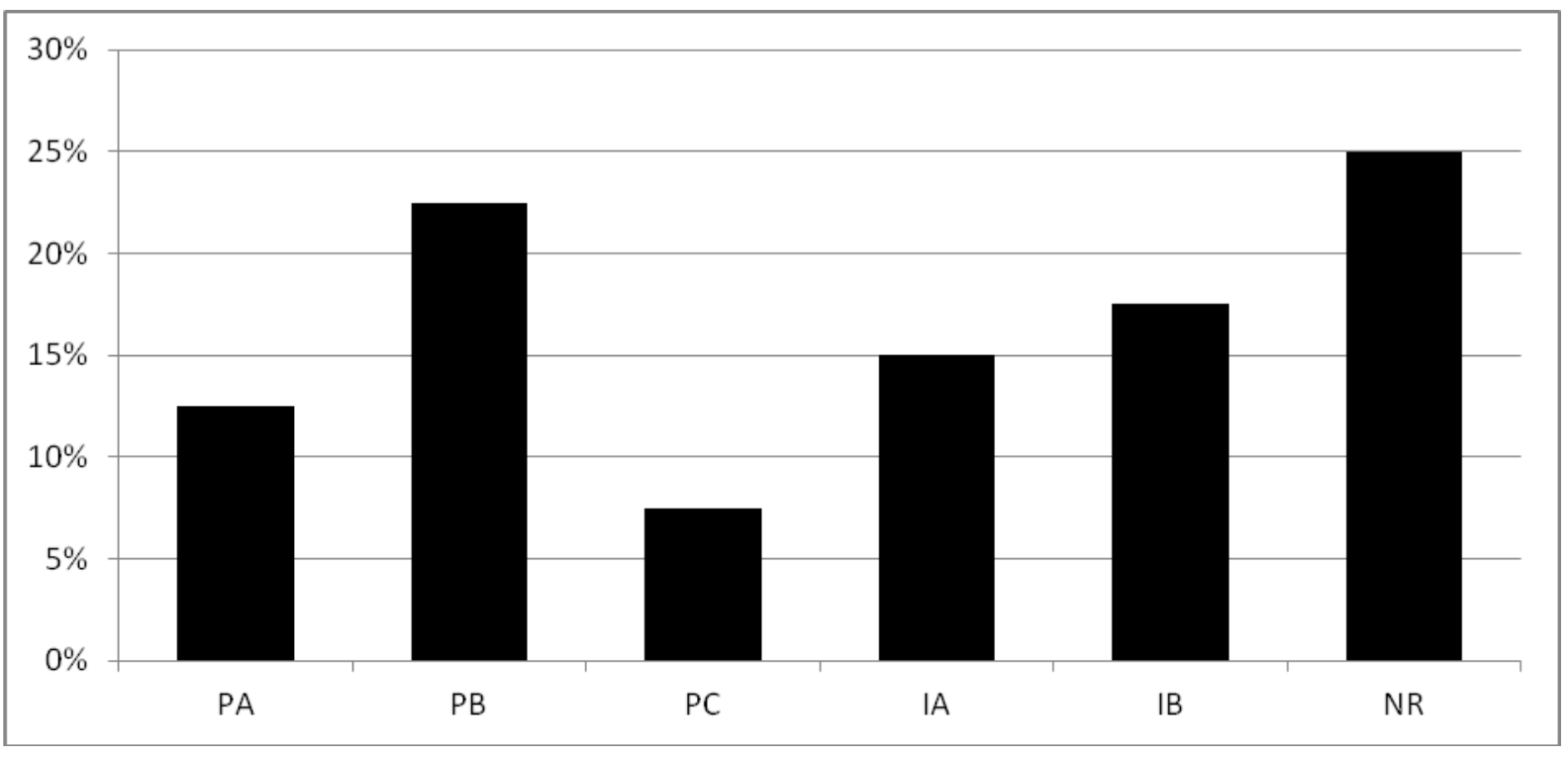

Figura 1 - Caracterização sorológica dos isolados de Escherichia coli provenientes do leite de tanques resfriadores de pequenas propriedades rurais do município de Canguçu, Rio Grande do Sul.

PA - Soro Polivalente A, PB - Soro Polivalente B, PC - Soro Polivalente C, IA - Soro Polivalente Invasora A, IB Soro Polivalente Invasora B, NR - Não Reagente.

No teste de sensibilidade a antimicrobianos observou-se maior sensibilidade ao sulfazotrim (SUT) e imipenem (IPM), pois $80 \%$ dos isolados mostraram-se sensíveis. Ainda, mais de $60 \%$ dos isolados apresentaram sensibilidade a sete (sulfazotrim, nitrofurantoína, ciprofloxacina, polimixina B, norfloxacina, ampicilina, imipenem) dos 12 antimicrobianos testados, 0 fármaco com menor ação foi a cefotaxima, para a qual apenas 32,5\% dos isolados apresentaram sensibilidade (Figura 2).

Okura e Ávila (2004) analisaram 70 amostras de E. coli isoladas de leite cru e encontraram $30 \%$ de resistência à ampicilina (AMP) e 5,7\% à sulfametrima (sulfadiazina+trimetoprim) (SZT), resultados semelhantes ao encontrado no presente trabalho. Oltramari et al. (2011) analisaram 56 amostras de leite pasteurizado de 22 laticínios localizados na região noroeste do estado do Paraná, sendo que dos 95 isolados de $E$. coli, 55,78\% apresentaram resistência à cefalotina (CFL) e 26,31\% à ampicilina (AMP).

Barreto et al. (2012) avaliaram 25 amostras de leite cru provenientes de 25 estabelecimentos comerciais de Cruz das Almas (BA), em 19 (76\%) amostras encontraram $E$. coli. Dos isolados de $E$. coli, 84,2\% foram sensíveis à nitrofurantoína (NIT), 89,5\% à ampicilina (AMP), 94,7\% ao imipenem (IPM) e à amicacina (AMI), sendo que $57,9 \%$ dos isolados foram 
resistentes à tetraciclina (TET). Os autores sugerem que o uso de antimicrobianos na alimentação animal podem ter contribuído pela elevada resistência à tetraciclina.

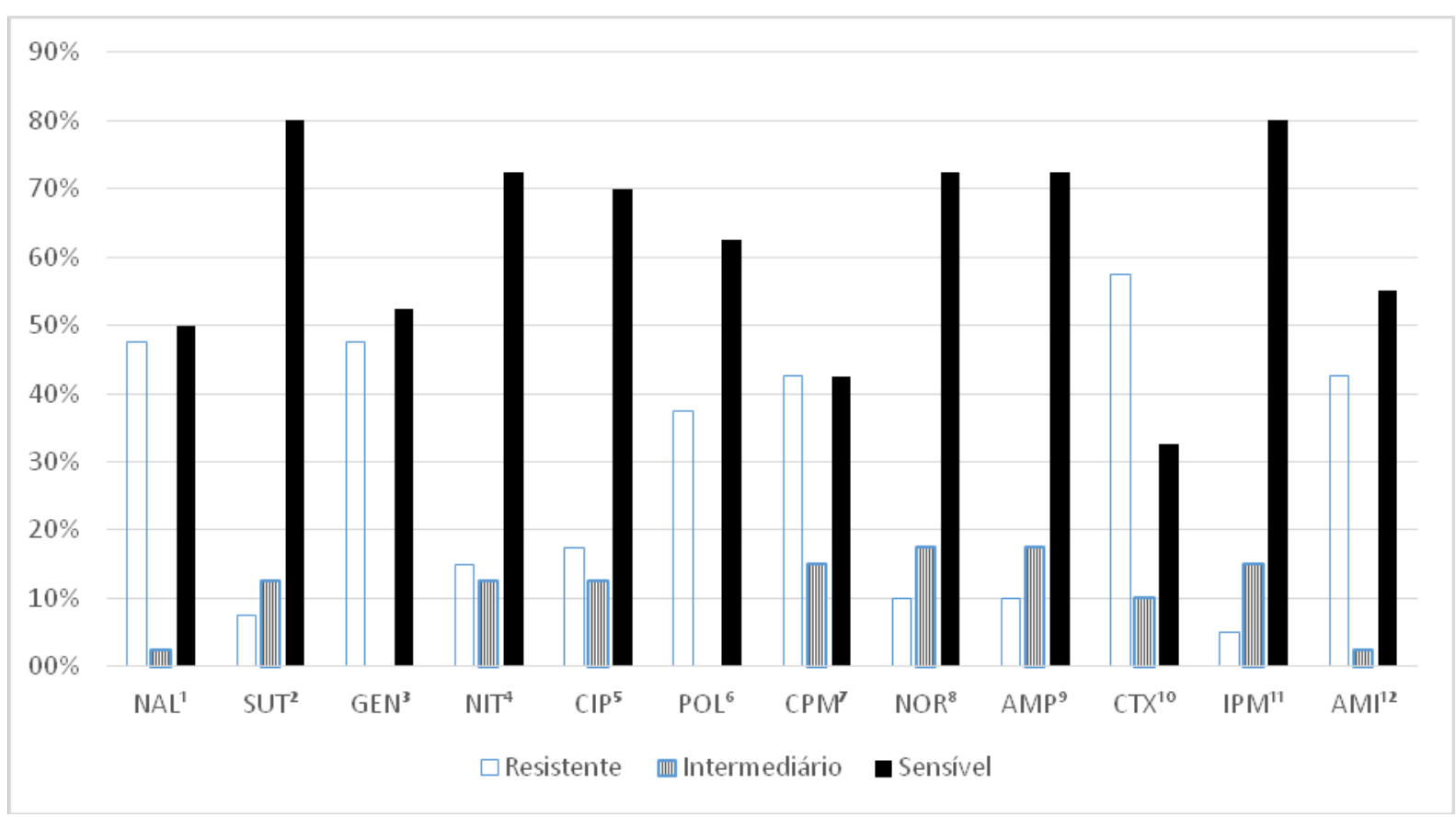

Figura 2 - Sensibilidade geral de isolados de Escherichia coli provenientes do leite de tanques resfriadores de pequenas propriedades rurais do município de Canguçu, Rio Grande do Sul.

${ }^{1}$ Ácido Nalidíxico, ${ }^{2}$ Sulfazotrim, ${ }^{3}$ Gentamicina, ${ }^{4}$ Nitrofurantoína, ${ }^{5}$ Ciprofloxacina, ${ }^{6}$ Polimixina B, ${ }^{7}$ Cefepime, ${ }^{8}$ Norfloxacina, ${ }^{9}$ Ampicilina, ${ }^{10}$ Cefotaxima, ${ }^{11}$ Imipenem, ${ }^{12}$ Amicacina.

Os resultados obtidos do perfil de resistência aos antimicrobianos dos isolados de E. coli, identificados através da sorotipificação, estão demonstrados na Figura 3. 


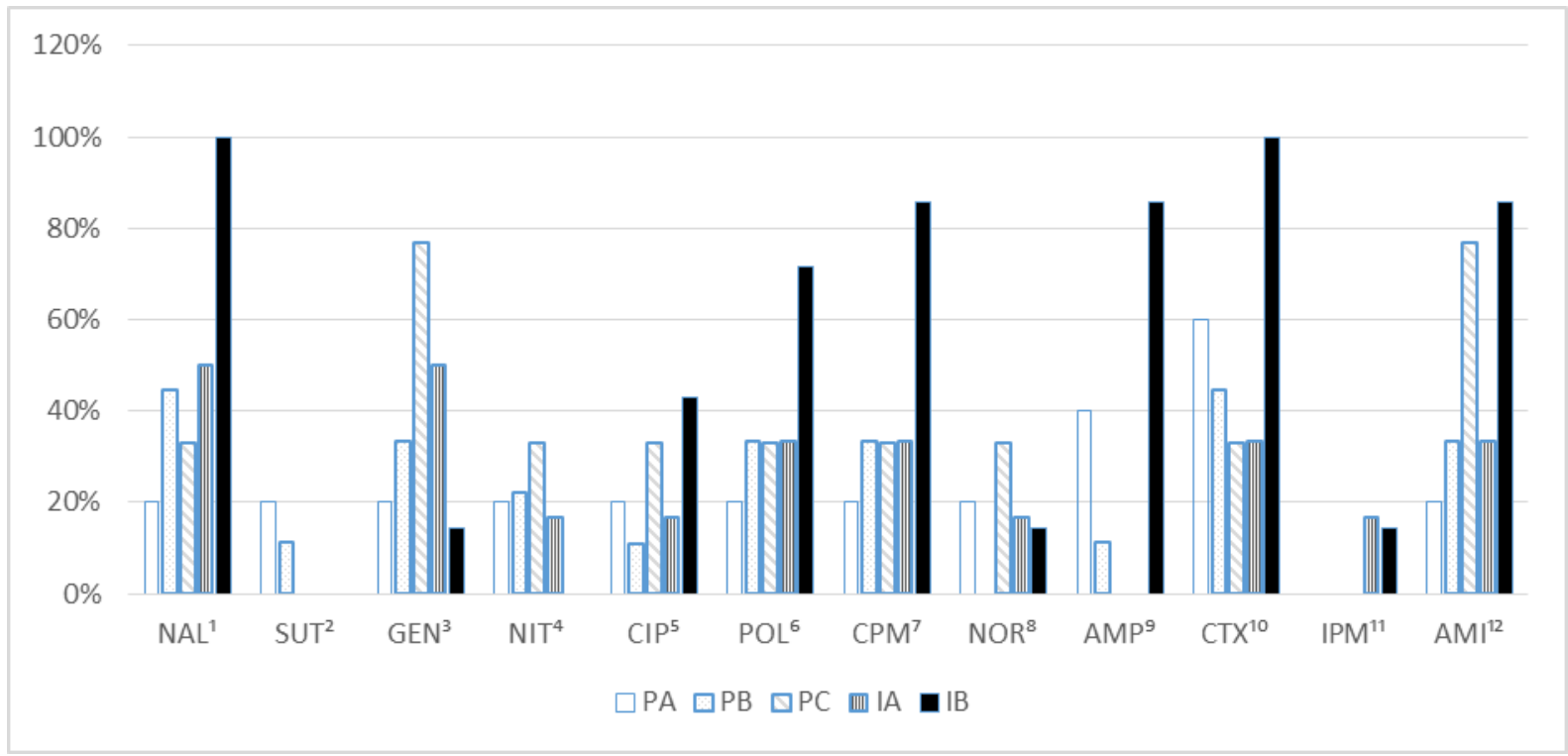

Figura 3 - Resistência dos isolados de Escherichia coli, identificados através da sorotipificação, provenientes do leite de tanques resfriadores de pequenas propriedades rurais do município de Canguçu, Rio Grande do Sul. ${ }^{1}$ Ácido Nalidíxico, ${ }^{2}$ Sulfazotrim, ${ }^{3}$ Gentamicina, ${ }^{4}$ Nitrofurantoína, ${ }^{5}$ Ciprofloxacina, ${ }^{6}$ Polimixina B, ${ }^{7}$ Cefepime, ${ }^{8}$ Norfloxacina, ${ }^{9}$ Ampicilina, ${ }^{10}$ Cefotaxima, ${ }^{11}$ Imipenem, ${ }^{12}$ Amicacina.

E. coli enteropatogênica é considerada uma importante causa de diarreia infantil, sendo associada com a subnutrição e condições precárias de saneamento. No paciente acometido ocorre mal-estar, vômitos e diarreia aquosa, podendo existir a presença de sangue após 12 a 26 horas da ingestão do microrganismo (DEBROY; MADDOX, 2001).

Entre os isolados de $E$. coli enteropatogênica, aqueles identificados pelo soro Polivalente $C$ (sorogrupos 086, 0126, 0127, 0128) demonstraram maior resistência que os demais, principalmente contra o grupo dos Aminoglicosídeos (gentamicina 78\% e amicacina $75 \%$ ). Os isolados identificados pelo soro Polivalente A (sorogrupos 026, 055, 0111, 0119) demonstraram menor resistência frente aos antimicrobianos testados, apresentando resistência superior a $20 \%$ somente para ampicilina e cefotaxima (Figura 3 ).

E. coli enteroinvasiva (EIEC) tem como mecanismo principal de patogenicidade a invasão de células da mucosa intestinal, ocorrendo penetração em células epiteliais, seguida pela lise do vacúolo endocítico, multiplicação intracelular, movimento direcional no citoplasma e invasão das células adjacentes. Pacientes acometidos por esse patotipo apresentam a doença invasiva do cólon, chamada de disenteria bacilar. Os sintomas característicos desses pacientes são febre, dor abdominal e diarreia aquosa, podendo ocorrer fezes com muco e 
sangue, sendo que a disenteria ocasionada por este grupo é geralmente auto-limitante (SABRÁ, 2002).

Entre os isolados de E. coli enteroinvasiva, aqueles identificados pelo soro Polivalente Invasora B (sorogrupos 0112ac, 0124, 0143, 0164, 0167) demonstraram maior resistência aos antimicrobianos testados. Mais de $80 \%$ dos isolados identificados pelo soro IB demonstraram resistência à cinco dos 12 antimicrobianos testados (ácido nalidíxico, cefepime, ampicilina, cefotaxima, amicacina), sendo que $100 \%$ dos isolados foi resistente ao ácido nalidíxico e a cefotaxima.

\section{CONCLUSÃO}

Com base nos resultados, conclui-se que mais de $50 \%$ das amostras de leite cru refrigerado das pequenas propriedades rurais do município de Canguçu, estado do Rio Grande do Sul, apresentaram E. coli. Em 42,5\% dos isolados foi identificada E. coli enteropatogênica (ETEC) e em $32,5 \%$ E. coli enteroinvasiva (EIEC). Quanto ao perfil de sensibilidade dos isolados, os antimicrobianos sulfazotrim e imipenem foram os que apresentaram maior eficiência nos testes in vitro.

\section{CHARACTERIZATION AND SENSIBILITY OF Escherichia coli STRAINS ISOLATED FROM MILK COOLING TANKS FROM SMALL PROPRIETIES IN THE CITY OF CANGUÇU-RS}

\section{ABSTRACT}

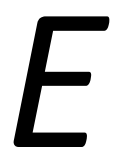

scherichia coli is a Gram-negative enterobacter with pathogenic potential. It can be found in food being responsible mainly for diarrheal diseases in children, immunosuppressed adults and also in animals. This study aimed to identify the presence of $E$. coli in raw milk cooling tanks, from small farms in the city of Canguçu, Rio Grande do Sul and evaluate its sensibility to antimicrobials commonly used to treat the infections caused by this microorganism. The serological analysis identified enteropathogenic $E$. coli (ETEC) in $42.5 \%$ of the isolates and enteroinvasive $E$. coli (EIEC) in $32.5 \%$. In the analysis of biossensitivity, the best results were obtained with the antimicrobials sulfazotrim and imipenem, both with $80 \%$ of efficiency. Regarding resistance, $57.5 \%$ of the isolates were resistant to cefotaxime and $47.5 \%$ were resistant to gentamicin 
and nalidixic acid. The isolates had low resistance to some antimicrobials usually used for the treatment of colibacillosis in humans and animals.

Keywords: Antibiogram. Serology. Public health. Raw milk.

\section{CARACTERIZACIÓN Y SENSIBILIDAD DE Escherichia coli AISLADAS DE LA LECHE DE LOS TANQUES DE ENFRIAMIENTO DE LAS PEQUEÑAS PROPRIEDADES DE LA CIUDAD DE CANGUÇU - RS}

\section{RESUMEN}

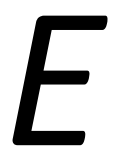

scherichia coli es una enterobacteria Gram-negativa con potencial patógeno, que se puede encontrar en los alimentos. Es principalmente responsable de las enfermedades diarreicas en niños y adultos inmunodeprimidos y también en animales. Este estudio tuvo como objetivo identificar la presencia de $E$. coli en la leche cruda, en tanques de enfriamiento de leche, en pequeñas propiedades lecheras en el municipio de Canguçu, Rio Grande do Sul y evaluar su sensibilidad a los antibióticos comúnmente utilizados para tratar infecciones causadas por este microorganismo. El análisis serológico identificó $E$. coli enteropatogénica (ETEC) en $42,5 \%$ de los aislados y $E$. coli enteroinvasiva (EIEC) al 32,5\%. En el análisis de biosensibilidad, los mejores resultados se obtuvieron con los antimicrobianos sulfazotrima e imipenem, ambos con una eficiencia del $80 \%$. En relación a la resistencia, $57,5 \%$ eran resistentes a cefotaxima y $47,5 \%$ fueron resistentes a la gentamicina y ácido nalidíxico. Las colonias aisladas tenían baja resistencia a algunos antimicrobianos utilizados habitualmente para el tratamiento de la colibacilosis en humanos y animales.

Palabras clave: Antibiograma. Serología. Salud pública. Leche cruda.

\section{REFERÊNCIAS}

BARRETO, N. S. E.; SANTOS, G. C. F.; CREPALDI, A. L.; SANTOS, R. A. R. Qualidade microbiológica e suscetibilidade antimicrobiana do leite in natura comercializado em Cruz das Almas, Bahia. Semina: Ciências Agrárias, v. 33, n. 6, p. 2315-2326, 2012.

BRASIL. Ministério da Agricultura quer fomentar o consumo de leite - Consumo de leite, 2015. Disponível em: <www.agricultura.gov.br>. Acesso em: 15 de abril de 2016. 
CAMPOS, M. R. H.; KIPNIS, A.; ANDRÉ, M. C. D. P. B.; VIEIRA, C. A. S.; JAYME, L. B.; SANTOS, P. P.; SERAFINI, A. B. Caracterização fenotípica pelo antibiograma de cepas de Escherichia coli isoladas de manipuladores, de leite cru e de queijo "Minas Frescal" em um laticínio de Goiás, Brasil. Ciência Rural, v. 36, n. 4, p. 1221-1227, 2006.

DEBROY, C.; MADDOX, C. W. Identification of virulence attributes of gastrointestinal Escherichia coli isolates of veterinary significance. Animal Health Research Reviews, v. 2, n. 2, p. 129-140, 2001.

FAO-ORGANIZAÇÃO DAS NAÇÕES UNIDAS PARA ALIMENTAÇÃO E AGRICULTURA. La leche em cifras, 2015. Disponível em: <http://www.fao.org/resources/infographics/infographicsdetails/es/c/273897/>. Acesso em: 20 de abril de 2016.

FONSECA, L. F. L.; SANTOS, M. V. Qualidade do leite e controle da mastite. São Paulo: Lemos Editorial, 2000. 175p.

HUANG, D. B.; MOHANTY, A.; DUPONT, H. L.; PKHUYSEN, P. C.; CHIANG, T. A. A review of a emerging enteric pathogen: enteroaggregative Escherichia coli. Journal of Medical Microbiology, v. 55, p. 1303-1311, 2006.

IBGE-INSTITUTO BRASILEIRO DE GEOGRAFIA E ESTATÍ́STICA. Aniversário de Canguçu. 2013. Disponível em: http://teen.ibge.gov.br/calendario-teen-7a12/evento/3329-aniversario-decangucu-rs.html. Acesso em: 20 de abril 2016.

IBGE-INSTITUTO BRASILEIRO DE GEOGRAFIA E ESTATÍSTICA. Estatística da Produção Pecuária, 2016. Disponível em: <http://www.ibge.gov.br>. Acesso em: 05 de abril de 2016.

KASNOWSKI, M. C.; FRANCO, R. M.; OLIVEIRA, L. A. T.; VALENTE, A. M.; CARVALHO, J. C. Escherichia coli uma revisão bibliográfica. Higiene Alimentar, v. 21, n. 154, p. 144-148, 2007.

NATARO, J. B.; KAPER, J. B. Diarrheagenic Escherichia coli. Clinical Microbiology Review, v. 11, p. 142-201, 1998.

NCCLS-NATIONAL COMMITTEE FOR CLINICAL LABORATORY STANDARDS. Approved Standard M2-A8. Performance Standards for Antimicrobial Disk Susceptibility Tests. Wayne, PA: National Committee for Clinical Laboratory Standards, 2003. 310p.

OKURA, M. H.; ÁVILA, F. A. Isolamento de enteropatógenos em leite cru produzido nas microrregiões do triângulo mineiro, MG. FAZU em Revista, Uberaba, n. 1, p. 11-20, 2004.

OKURA, M. H.; RIGOBELO, E. C.; ÁVILA, F. A. Isolamento e identificação de patógenos em leite cru produzido nas microrregiões do triângulo mineiro, MG. ARS Veterinária, v. 21, n. 3, p. 324-331, 2005. 
OLTRAMARI, K; RIOS, M. C; BERGAMASCO, R; JUNIOR, M. M; ZANELLA, G. N; MADRONA, G.; MIKCHA, J. M. G. Resistência a antimicrobianos em Escherichia coli isolada de leite pasteurizado. Revista Tecnológica, Edição Especial V Simpósio de Engenharia, Ciência e Tecnologia de Alimentos, p. 57-61, 2011.

OMS-ORGANIZAÇÃO MUNDIAL DA SAÚDE. Consumo de leite. Disponível em: <http://www.paho.org/bra/2016>. Acesso em: 20 de abril de 2016.

PROBAC-PROBAC DO BRASIL. Bulas, 2016. Disponível em: <http://www.probac.com.br>. Acesso em: 20 de abril de 2016.

QUINN, P. J.; MARKEY, B. K.; LEONARD, F. C.; FITZPATRICK, E. S.; FANNING, S.; HARTIGAN, P. J. Veterinary Microbiology and Microbiology Disease. 2. ed. lowa: Willy-Blackwell, 2011. 1231p.

SABRÁ, A. ECEP, ECET, ECEA, ECEH, ECEI, ECAD: E. coli revisitada no contexto da diarreia aguda. Jornal de Pediatria, v. 77, n. 1, p. 5-7, 2002.

SCABIN, K. E. M.; KOZUSNY-ANDREANI, D. I.; RODRIGUES FRIAS, D. F. R. Microbiological quality of milk in nature during the process of obtaining and after cooling. Revista CES Medicina Veterinaria y Zootecnia, v. 7, n. 1, p. 11-21, 2012.

SILVA, Z. N.; CUNHA, A. S.; LINS, M. C.; CARNEIRO, L. A. M.; ALMEIDA, A. C. F.; QUEIROZ, M. L. $P$. Isolation and serological identification of enteropathogenic Escherichia coli in pasteurized milk in Brazil. Revista de Saúde Pública, v. 35, n. 4, p. 375-379, 2001.

VIRPARI, P. K.; NAYAK, J. B.; THAKER, H. C.; BRAHMBHATT, M. N. Isolation of pathogenic Escherichia coli from stool samples of diarrheal patients with history of raw milk consumption. Veterinary Word, v. 6, n. 9, p. 659-663, 2013.

Autor para correspondência: Cristina Mendes Peter. Laboratório de Bacteriologia e Saúde Populacional, Faculdade de Veterinária, UFPEL, Campus Universitário, 